\title{
OPTICAL SATELLTE Data Compression and Implementation
}




\section{OPTICAL SATELLTTE Data Compression and Implementation}

Shen-En Qian 
Library of Congress Cataloging-in-Publication Data

Qian, Shen-En.

Optical satellite data compression and implementation / Shen-En Qian. pages $\mathrm{cm}$

Includes bibliographical references and index.

ISBN 978-0-8194-9787-1

1. Data compression (Computer science). 2. Imaging systems Image quality.

3. Signal processing. 4. Coding theory. 5. Optical images. I. Title.

QA76.9.D33 2013

$629.43^{\prime} 7 \mathrm{dc} 23$

2013944363

Published by

SPIE The International Society for Optical Engineering

P.O. Box 10

Bellingham, Washington 98227-0010 USA

Phone: +1 3606763290

Fax: +1 3606471445

Email: spie@spie.org

Web: http://spie.org

Copyright (C) 2013 Society of Photo-Optical Instrumentation Engineers (SPIE)

All rights reserved. No part of this publication may be reproduced or distributed in any form or by any means without written permission of the publisher.

The content of this book reflects the work and thought of the author(s). Every effort has been made to publish reliable and accurate information herein, but the publisher is not responsible for the validity of the information or for any outcomes resulting from reliance thereon.

Printed in the United States of America.

First printing 


\section{Contents}

Preface xiii

List of Terms and Acronyms xvii

1 Needs for Data Compression and Image Quality Metrics 1

1.1 Needs for Satellite Data Compression 1

1.2 Quality Metrics of Satellite Images 4

1.3 Full-Reference Metrics $\quad 5$

1.3.1 Conventional full-reference metrics 6

1.3.1.1 Mean-square error (MSE) 6

1.3.1.2 Relative-mean-square error (ReMSE) 7

$\begin{array}{lll}\text { 1.3.1.3 Signal-to-noise ratio (SNR) } & 7\end{array}$

1.3.1.4 Peak signal-to-noise ratio (PSNR) 7

$\begin{array}{lll}\text { 1.3.1.5 Maximum absolute difference (MAD) } & 7\end{array}$

1.3.1.6 Percentage maximum absolute difference (PMAD) 8

1.3.1.7 Mean absolute error (MAE) 8

1.3.1.8 Correlation coefficient (CC) 8

1.3.1.9 Mean-square spectral error (MSSE) 9

1.3.1.10 Spectral correlation (SC) 9

1.3.1.11 Spectral angle (SA) 9

1.3.1.12 Maximum spectral information divergence (MSID) 10

1.3.1.13 ERGAS for multispectral image after pan-sharpening 10

1.3.2 Perceived-visual-quality-based full-reference metrics 11

1.3.2.1 Universal image-quality index 11

1.3.2.2 Multispectral image-quality index 12

1.3.2.3 Quality index for multi- or hyperspectral images 14

$\begin{array}{lll}\text { 1.3.2.4 Structural similarity index } & 15\end{array}$

1.3.2.5 Visual information fidelity 17

$\begin{array}{lll}1.4 & \text { Reduced-Reference Metrics } & 18\end{array}$

1.4.1 Four RR metrics for spatial-resolution-enhanced images 20

1.4.2 RR metric using the wavelet-domain natural-image statistic model 22

1.5 No-Reference Metrics $\quad 24$

1.5.1 Statistic-based methods 24 
1.5.1.1 Entropy 24

1.5.1.2 Energy compaction 25

1.5.1.3 Coding gain 25

1.5.2 NR metric for compressed images using JPEG 26

1.5.3 NR metric for pan-sharpened multispectral image 27

1.5.3.1 Spectral distortion index 28

1.5.3.2 Spatial distortion index 29

1.5.3.3 Jointly spectral and spatial quality index 29

$\begin{array}{ll}\text { References } & 29\end{array}$

2 Lossless Satellite Data Compression 33

2.1 Introduction 33

2.2 Review of Lossless Satellite Data Compression 35

2.2.1 Prediction-based methods $\quad 35$

2.2.2 Transform-based methods 38

$\begin{array}{lll}2.3 & \text { Entropy Encoders } & 40\end{array}$

2.3.1 Adaptive arithmetic coding $\quad 40$

2.3.2 Golomb coding 41

2.3.3 Exponential-Golomb coding 42

2.3.4 Golomb power-of-two coding $\quad 42$

2.4 Predictors for Hyperspectral Datacubes 44

2.4.1 1D nearest-neighboring predictor 45

2.4.2 2D/3D predictors $\quad 45$

2.4.3 Predictors within a focal plane image $\quad 45$

$\begin{array}{lll}2.4 .4 & \text { Adaptive selection of predictor } & 47\end{array}$

2.4.5 Experimental results of the predictors 48

2.4.5.1 Compression results using fixed coefficient predictors 49

2.4.5.2 Compression results using variable coefficient predictors 50

2.4.5.3 Compression results using adaptive selection of predictor 51

2.5 Lookup-Table-Based Prediction Methods 53

2.5.1 Single-lookup-table prediction $\quad 53$

2.5.2 Locally averaged, interband-scaling LUT prediction 54

2.5.3 Quantized-index LUT prediction 56

2.5.4 Multiband LUT prediction 56

2.6 Vector-Quantization-Based Prediction Methods 57

2.6.1 Linear prediction $\quad 57$

2.6.2 Grouping based on bit-length 58

2.6.3 Vector quantization with precomputed codebooks 58

2.6.4 Optimal bit allocation $\quad 59$

2.6.5 Entropy coding $\quad 59$

$\begin{array}{lll}2.7 & \text { Band Reordering } & 60\end{array}$

2.8 Transform-Based Lossless Compression Using the KLT and DCT 61 
2.9 Wavelet-Transform-Based Methods 62

2.9.1 Wavelet decomposition structure 63

2.9.2 Lossy-to-lossless compression: 3D set-partitioning embedded block

2.9.3 Lossy-to-lossless compression: 3D embedded zeroblock coding 66

$\begin{array}{ll}\text { References } & 68\end{array}$

3 International Standards for Spacecraft Data Compression $\quad \mathbf{7 5}$

3.1 CCSDS and Three Data Compression Standards 75

3.2 Lossless Data Compression Standard 76

$\begin{array}{lll}3.2 .1 & \text { Preprocessor } & 76\end{array}$

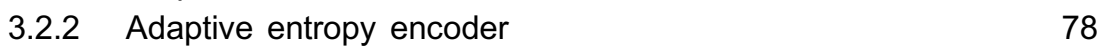

3.2.2.1 Variable-length coding 78

$\begin{array}{ll}3.2 .2 .2 \text { Coding options } & 80\end{array}$

3.2.2.3 Coded dataset format 81

3.2.3 Performance evaluation 81

3.2.3.1 1D data: Goddard High-Resolution Spectrometer 82

3.2.3.2 1D data: Acousto-Optical Spectrometer 83

3.2.3.3 1D data: Gamma-Ray Spectrometer 83

3.2.3.4 2D image: Landsat Thematic Mapper 84

3.2.3.5 2D image: Heat-Capacity-Mapping Radiometer $\quad 84$

3.2.3.6 2D image: Wide-Field Planetary Camera 85

3.2.3.7 2D image: Soft X-Ray Solar Telescope $\quad 85$

3.2.3.8 3D image: hyperspectral imagery 85

3.3 Image Data Compression Standard 86

3.3.1 Features of the standard 86

$\begin{array}{lll}3.3 .2 & \text { IDC compressor } & 87\end{array}$

3.3.3 Selection of compression options and parameters 91

3.3.3.1 Segment headers 92

3.3.3.2 Integer or float DWT 93

3.3.3.3 Parameters for controlling compression ratio

3.3.3.4 Parameters for lossless compression 93

3.3.3.5 Segment size $S \quad 94$

3.3.3.6 Golomb code parameter 94

3.3.3.7 Custom subband weight 95

3.3.4 Performance evaluation 95

3.3.4.1 Lossless compression results 95

3.3.4.2 Lossy compression results 97

3.4 Lossless Multispectral/Hyperspectral Compression Standard 98

3.4.1 Compressor composition 98

$\begin{array}{ll}3.4 .2 & \text { Adaptive linear predictor } \\ 3.4 .3 & 99\end{array}$

$\begin{array}{lll}3.4 .3 & \text { Encoder } & 102\end{array}$

3.4.4 Performance evaluation 103

$\begin{array}{ll}\text { References } & 104\end{array}$ 
4 Vector Quantization Data Compression 107

4.1 Concept of Vector Quantization Compression 107

4.2 Review of Conventional Fast Vector Quantization Algorithms 110

4.3 Fast Vector-Quantization Algorithm Based on Improved Distance to MDP 112

4.3.1 Analysis of the generalized Lloyd algorithm for fast training 113

4.3.2 Fast training based on improved distance to MDP 115

4.3.3 Experimental results 117

4.3.4 Assessment of preservation of spectral information 120

4.4 Fast Vector Quantization Based on Searching Nearest Partition Sets 123

4.4.1 Nearest partition sets 124

4.4.2 Upper-triangle matrix of distances 126

4.4.3 p-least sorting 127

4.4.4 Determination of NPS sizes 128

4.4.5 Two fast VQ search algorithms based on NPSs 130

4.4.5.1 Algorithm 1

4.4.5.2 Algorithm $2 \quad 132$

4.4.6 Experimental results 133

4.4.7 Comparison with published fast search methods 136

4.5 3D VQ Compression Using Spectral-Feature-Based Binary Code 138

4.5.1 Spectral-feature-based binary coding 138

4.5.2 Fast 3D VQ using the SFBBC 140

4.5.3 Experimental results of the SFBBC-based VQ compression algorithm 141

4.6 Correlation Vector Quantization 143

4.6.1 Process of CVQ 143

4.6.2 Performance of CVQ 146

4.7 Training a New Codebook for a Dataset to Be Compressed 147

4.8 Multiple-Subcodebook Algorithm Using Spectral Index 149

4.8.1 Spectral indices and scene segmentation 149

4.8.1.1 Manual multithresholding 150

4.8.1.2 Isoclustering 151

4.8.1.3 Histogram-based segmentation with same-size regions 151

4.8.1.4 Modified histogram-based segmentation $\quad 152$

4.8.2 Methodology of MSCA 153

4.8.3 Improvement in processing time 154

4.8.4 Experimental results of the MSCA 154

4.8.5 MSCA with training set subsampling 157

4.8.6 MSCA with training set subsampling plus SFBBC

4.8.7 MSCA with training set subsampling plus SFBBC for both codebook training and coding 
4.9 Successive Approximation Multistage Vector Quantization 162

4.9.1 Compression procedure 162

$\begin{array}{lll}4.9 .2 & \text { Features } & 164\end{array}$

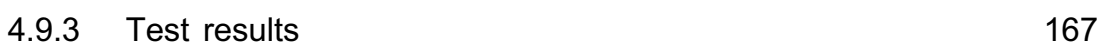

4.10 Hierarchical Self-Organizing Cluster Vector Quantization 168

4.10.1 Compression procedure 168

$\begin{array}{lll}4.10 .2 & \text { Features } & 170\end{array}$

$\begin{array}{ll}\text { References } & 171\end{array}$

5 Onboard Near-Lossless Data Compression Techniques 177

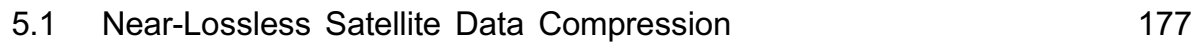

5.2 Cluster SAMVQ 178

5.2.1 Organizing continuous data flow into regional datacubes 178

5.2.2 Solution for overcoming the blocking effect 180

5.2.3 Removing the boundary between adjacent regions 181

5.2.4 Attaining a fully redundant regional datacube for preventing data loss in the downlink channel 182

5.2.5 Compression performance comparison between SAMVQ and cluster SAMVQ 184

$\begin{array}{lll}5.3 & \text { Recursive HSOCVQ } & 185\end{array}$

5.3.1 Reuse of codevectors of the previous region to attain a seamless conjunction between regions 185

5.3.2 Training codevectors for a current frame and applying them to subsequent frames 186

5.3.3 Two schemes of carrying forward reused codevectors trained in the previous region 188

5.3.4 Compression performance comparison between baseline and recursive HSOCVQ 190

5.4 Evaluation of Near-Lossless Performance of SAMVQ and HSOCVQ 191

5.4.1 Evaluation method and test dataset 191

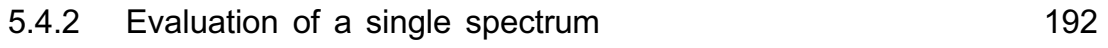

5.4.3 Evaluation of an entire datacube 194

5.5 Evaluation of SAMVQ with Regard to the Development of

$\begin{array}{ll}\text { International Standards of Spacecraft Data Compression } & 197 \\ \text { 5.5.1 CCSDS test datasets } & 198\end{array}$

5.5.2 Test results of hyperspectral datasets 199

5.5.3 Compression of multispectral datasets using SAMVQ 203

References 209

6 Optimizing the Performance of Onboard Data Compression 211

6.1 Introduction 211

6.2 The Effect of Raw Data Anomalies on Compression Performance 212

6.2.1 Anomalies in the raw hyperspectral data 212

6.2.2 Effect of spikes on compression performance 213 
6.2.3 Effect of saturation on compression performance 219

6.2.4 Summary of anomaly effects 222

6.3 The Effect of Preprocessing and Radiometric Conversion on Compression Performance 223

6.3.1 Artifacts introduced in preprocessing and radiometric conversion 223

6.3.2 Evaluation using crop leaf area index in agriculture applications 224

6.3.3 Evaluation using target detection 228

6.4 The Effect of Radiance-Data Random Noise on Compression Performance 231

6.4.1 Data processing procedure 231

6.4.2 Evaluation results using statistical measures 232

6.4.3 Evaluation results using target detection 233

6.5 Effect of Keystone and Smile on Compression Performance 235

6.6 Enhancing the Resilience of Compressed Data to Bit Errors
in the Downlink Channel

6.6.1 Triple-module redundancy used in the header of the
codebook and index map

6.6.2 Convolutional codes 241

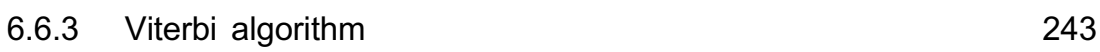

6.6.4 Simulation results 244

$\begin{array}{ll}\text { References } & 247\end{array}$

\section{Color Plates}

7 Data Compression Engines aboard a Satellite 249

7.1 Top-Level Topology of Onboard Data Compressors 249

7.2 Vector Distance Calculators $\quad 252$

7.2.1 Along-spectral-bands vector distance calculator 252

7.2.2 Across-spectral-bands vector distance calculator 254

7.3 Codevector Trainers 256

7.3.1 Along-spectral-bands codevector trainer 256

7.3.2 Across-spectral-bands codevector trainer 259

7.4 Vector Quantization Data Compression Engines 262

7.5 Real-time Onboard Compressor 264

$\begin{array}{lll}7.5 .1 & \text { Configuration } & 264\end{array}$

7.5.2 Network switch 266

7.6 Hardware Implementation Process of SAMVQ and HSOCVQ 268

$\begin{array}{lll}\text { 7.6.1 Codevector training } & 268\end{array}$

$\begin{array}{lll}7.6 .2 & \text { SAMVQ } & 269\end{array}$

$\begin{array}{lll}\text { 7.6.3 HSOCVQ } & 270\end{array}$

7.7 Scenario Builder: A Real-Time Data Compression Emulator 272

7.7.1 Scenario Builder overview 273

$\begin{array}{ll}\text { 7.7.2 Scenario Builder applications } & 273\end{array}$ 
7.7.3 Architecture and data flow of Scenario Builder 275

7.7.4 SORTER engine and cluster SAMVQ compression engine 276

7.7.5 Recursive HSOCVQ compression engine 280

7.7.6 Scenario Builder products 282

7.7.6.1 SORTER 283

7.7.6.2 SAMVQ engine with external RAM 283

7.7.6.3 HSOCVQ engine with external RAM 284

7.7.6.4 Clock-accurate hardware timing 284

7.7.6.5 Hardware bottleneck emulation 285

7.7.7 Scenario simulation user interface 285

7.8 Using Scenario Builder to Optimally Design Onboard Data
Compressor Architecture

7.8.1 Parameters of the design 287

7.8.2 SORTER as the front-end compressor 287

7.8.3 Second-level compressor 288

$\begin{array}{lll}7.8 .4 & \text { Proposed system } & 290\end{array}$

$\begin{array}{ll}\text { References } & 292\end{array}$

8 User Acceptability Study of Satellite Data Compression 295

8.1 User Assessment of Compressed Satellite Data 295

$\begin{array}{lll}8.2 & \text { Double-Blind Test } & 297\end{array}$

8.3 Evaluation Criteria 298

$\begin{array}{lll}8.4 & \text { Evaluation Procedure } & 298\end{array}$

8.5 Multidisciplinary Evaluation $\quad 301$

$\begin{array}{lll}\text { 8.5.1 Precision agriculture } & 301\end{array}$

$\begin{array}{lll}8.5 .2 & \text { Forest regeneration } & 305\end{array}$

8.5.3 Geology 306

8.5.4 Military target detection 308

$\begin{array}{lll}\text { 8.5.5 Mineral exploration } 1 & 310\end{array}$

8.5.6 Ocean ship and wake detection 312

8.5.7 Mineral exploration $2 \quad 313$

8.5.8 Mineral exploration $3 \quad 314$

$\begin{array}{ll}\text { 8.5.9 Civilian target detection } & 315\end{array}$

8.5.10 Forest species classification $\quad 316$

8.5.11 Endmember extraction in mineral exploration 317

8.6 Overall Assessment Result and Ranking 319

8.7 Effect of Lossy Data Compression on Retrieval of Red-Edge Indices 324

$\begin{array}{lll}\text { 8.7.1 Test datacubes } & 324\end{array}$

$\begin{array}{lll}\text { 8.7.2 Red-edge indices } & 324\end{array}$

8.7.3 Evaluation using red-edge products 326

8.7.4 Evaluation results and analysis 327

8.7.4.1 From CASI datacubes $\quad 327$

8.7.4.2 From AVIRIS datacube 333

8.7.4.3 Spatial patterns of induced product errors $\quad 336$ 
8.7.5 Summary of the evaluation 338

References

9 Hyperspectral Image Browser for Online Satellite Data Analysis and Distribution

9.1 Motivation for Web-Based Hyperspectral Image Analysis 345

9.2 Web-Based Hyperspectral Image Browser and Analysis 346

9.3 HIBR Functions and Data Flow 349

9.3.1 Hyperspectral data compressor 350

9.3.2 Hyperspectral catalog web server 352

9.3.3 Overall data flow 353

9.4 User Scenarios 353

9.5 Hyperspectral Image Browser Operations 354

9.5.1 HIBR visualization 354

9.5.2 User product search 356

9.5.3 User product generation 357

9.5.4 HIBR graphical user interface 358

$\begin{array}{lll}9.6 & \text { Summary } & 360\end{array}$

References $\quad 362$

Index 365 


\section{Preface}

Satellite data compression has been an important subject since the beginning of satellites in orbit, and it has become an even more active research topic. Following technological advancements, the trend of new satellites has led to an increase in spatial, spectral, and radiometric resolution, an extension in wavelength range, and a widening of ground swath to better serve the needs of the user community and decision makers. Data compression is often used as a sound solution to overcome the challenges of handling a tremendous amount of data. I have been working in this area since I was pursing my Ph. D. thesis almost 30 years ago.

Over the last two decades, I-as a senior research scientist and technical authority with the Canadian Space Agency — have led and carried out research and development of innovative data compression technology for optical satellites in collaboration with my colleagues at the agency, other government departments, my postdoctoral visiting fellows, internship students, and engineers at Canadian space industry. I invented and patented two series of near-lossless satellite data compression techniques and led the Canadian industry teams who implemented the techniques and built the onboard nearlossless compressors. I also led a multidisciplinary user team to assess the impact of the near-lossless compression techniques on ultimate satellite data applications. As the representative of Canada, I am an active member of the CCSDS working group for developing international data-compression standards for satellite data systems. Three international satellite data compression standards have been developed by the working group and published by the International Organization for Standardization (ISO). In collaborating with experts in this area in the world, I have co-chaired an SPIE conference on satellite data compression, communication, and signal processing since 2005. I have published over sixty papers and currently hold six U. S. patents, two European patents, and several pending patents in the subjects of satellite data compression and implementation. I feel that I have acquired sufficient knowledge and accumulated plenty experience in this area, and it is worth the effort to systematically organize them and put them into a book.

This book is my attempt to provide an end-to-end treatment of optical satellite data compression and implementation based on 30 years of firsthand 
experience and research outcomes. (It is a companion text to my book Optical Satellite Signal Processing and Enhancement, published by SPIE Press.) The contents of the book consist of nine chapters that cover a wide range of topics in this field. It serves as an introduction for readers who are willing to learn the basics and the evolution of data compression, and a guide for those working on onboard and ground satellite data compression, data handling and manipulation, and deployment of data-compression subsystems. The material is written to provide clear definitions and precise descriptions for advanced researchers and expert practitioners as well as for beginners. Chapters open with a brief introduction of the subject matter, followed by a review of previous approaches and their shortcomings, a presentation of recent techniques with improved performance, and finally a report on experimental results in order to assess their effectiveness and to provide conclusions.

Chapter 1 is the introduction to the book that describes the rationale and needs for satellite data compression and introduces a set of image quality metrics for assessing compressed satellite images. Chapter 2 presents a review of satellite lossless-data-compression techniques, considering both predictionbased and transform-based methods. Chapter 3 summarizes three international satellite-data-compression standards developed by CCSDS from the perspective of applying the standards. Chapter 4 describes vector quantization (VQ) based data-compression techniques that I have developed for compressing hyperspectral data. The focus of the research was to significantly reduce the computational complexity of conventional VQ algorithms in order for them to effectively compress hyperspectral datacubes. Many innovative yet practical solutions have been developed, including two of my granted patents: Successive Approximation Multi-stage Vector Quantization (SAMVQ) and Hierarchical Self-Organizing Cluster Vector Quantization (HSOCVQ). Chapter 5 describes how both of these techniques solve the blocking effect when applied to compressing continuous data flow generated aboard satellites and how they restrict the compression error to a level lower than that of the intrinsic noise of the original data to achieve so-called near-lossless compression. Chapter 6 addresses the optimization and implementation aspects of onboard data compression; aspects include the effect of anomalies of input data on compression performance, the location in the onboard dataprocessing chain where the compressor should be deployed, and the techniques to enhance error resilience in the data downlink transmission channel. Chapter 7 describes the hardware implementation of compression engines and onboard compressors that are based on SAMVQ and HSOCVQ. Chapter 8 reports a multidisciplinary user-acceptance study that assessed the impact of the compression techniques on various hyperspectral data applications to address the users' concern about possible information loss due to the lossy compression nature of SAMVQ and HSOCVQ. Chapter 9 
describes the Hyperspectral Image Browser (HIBR) system, which is capable of remotely displaying large hyperspectral datacubes via the Internet and of quickly processing the datacubes directly on the compressed form for users to identify the interested data, whose richness comes mostly from the spectral information.

There are many people I would like to thank for their contributions to the works included in this book. I would like to thank the Canadian Space Agency, where I have been working for the last 20 years; my colleagues Allan Hollinger, Martin Bergeron, Michael Maszkiewicz, Ian Cunningham, and Davinder Manak for their participation in data compression projects; my postdoctoral visiting fellows Pirouz Zarrinkhat and Charles Serele; and over forty intern students who have each left their mark. I would like to thank Robert Neville (retired), Karl Staenz (now at the University of Lethbridge), and Lixin Sun at the Canada Centre for Remote Sensing for collaborating on the Canadian hyperspectral program; Josée Lévesque and Jean-Pierre Ardouin at the Defence Research and Development Canada for their collaboration on assessing the impact of data compression. I thank David Goodenough at the Pacific Forestry Centre; John Miller and Baoxin $\mathrm{Hu}$ at York University for providing datasets and for actively collaborating on the data-compression user acceptability study; and Bormin Huang of the Cooperative Institute for Meteorological Satellite Studies at the University of Wisconsin-Madison for his discussion on satellite data compression.

I would also like to thank the participants in the user acceptability study: Andrew Dyk at the Pacific Forestry Centre; Jing Chen at the University of Toronto; Harold Zwick, Dan Williams, Chris Nadeau, and Gordon Jolly at MacDonald Dettwiler Associates; and Benoit Rivard and Jilu Feng at the University of Alberta. I thank Luc Gagnon, William Harvey, Bob Barrette, and Colin Black at MacDonald Dettwiler Associates (former EMS Technologies) for the development and fabrication of onboard compressor prototypes; and Melanie Dutkiewicz and Herbal Tsang for the development of a hyperspectral browser. I thank Valec Szwarc and Mario Caron at the Communication Research Centre (Canada) for discussions on enhancing resilience to bit errors of compressed data in the downlink channel; and Peter Oswald and Ron Buckingham for their discussion on onboard data compression. I would also like to thank Penshu Yeh at the NASA Goddard Space Flight Center, Aaron Kiely at the Jet Propulsion Laboratory, Carole Thiebaut and Gilles Moury at the French Space Agency (CNES), and Raffaele Vitulli at the European Space Agency for the collaboration within the CCSDS in developing international spacecraft-data standards and for their contributions to the CCSDS work included in this book.

I would also like to thank the three anonymous manuscript reviewers for their tireless work and strong endorsement of this book, their careful and meticulous chapter-by-chapter review on behalf of SPIE Press, and their 
detailed comments leading to the improvement and final results of the book in its current form. Many thanks as well to Tim Lamkins, Scott McNeill, and Dara Burrows at SPIE Press for turning my manuscript into this book.

Finally, I would like to thank my wife Nancy and daughter Cynthia for their help and support. They provided great encouragement and assistance during the period I wrote this book. The credit of this book should go to them.

Shen-En Qian (錢神恩) Senior Scientist, Canadian Space Agency Montreal, Canada September 2013 


\section{List of Terms and Acronyms}

$\begin{array}{ll}\text { \%E } & \text { Percentage error } \\ \% \text { SE } & \text { Percentage standard error } \\ \text { 3D CB-EZW } & \text { Three-dimensional context-based embedded zerotrees of } \\ & \text { wavelet transform } \\ \text { 3D-SPECK } & \text { Three-dimensional set-partitioned embedded block } \\ \text { AAC } & \text { Adaptive arithmetic coding } \\ \text { AC } & \text { Arithmetic coding } \\ \text { ACE-FTS } & \text { Atmospheric Chemistry Experiment-Fourier Transform } \\ \text { AIRS } & \text { Spectrometer } \\ \text { ALADIN } & \text { Atmospheric infrared sounder } \\ \text { ALI } & \text { Atmospheric Laser Doppler Lidar Instrument } \\ \text { ALOS } & \text { Advanced Land Imager } \\ \text { AMEE } & \text { Advanced Land-Observing Satellite } \\ \text { AOS } & \text { Automated morphological end-member extraction } \\ \text { AOTF } & \text { Advanced orbital system } \\ \text { APD } & \text { Acousto-optical tunable filter } \\ \text { APRAD } & \text { Avalanche photodiode } \\ \text { APSICL } & \text { Average percent relative absolute difference } \\ \text { A-RMSE } & \text { Adjacent pixel spectra in a cross-track line } \\ \text { ARSIS } & \text { Absolute root mean square error } \\ & \text { Amélioration de la résolution spatial par injection de } \\ \text { ARTEMIS } & \text { structures } \\ \text { Advanced Responsive Tactically Effective Military Imaging } & \text { Spectrometer } \\ \text { ATGP } & \text { Application-specific integrated circuit } \\ \text { AVIRIS } & \text { Automatic target generation process } \\ \text { AVNIR } & \text { Airborne visible/infrared imaging spectrometer } \\ \text { AWGN } & \text { Advanced visible and near-infrared radiometer } \\ \text { BCM } & \text { Additive white Gaussian noise } \\ \text { BDM } & \text { Band correlation minimization } \\ \text { BER } & \text { Band dependence minimization } \\ \text { BIP } & \text { Bit-error rate } \\ & \text { Band interleaved by pixel } \\ & \end{array}$




\begin{tabular}{|c|c|}
\hline BIPLGC & Binary-input power-limited Gaussian channel \\
\hline $\mathrm{BP}$ & Belief propagation \\
\hline BPE & Bit-plane encoder \\
\hline BPOC & Base-bit plus overflow-bit coding \\
\hline bpppb & Bits per pixel per band \\
\hline BPSK & Binary phase shift keying \\
\hline BRDF & Bidirectional reflectance distribution function \\
\hline BSQ & Band sequential \\
\hline CALIOP & Cloud-Aerosol Lidar with Orthogonal Polarization \\
\hline CASI & Compact airborne spectrographic imager \\
\hline CBERS & China-Brazil Earth Resources Satellite \\
\hline $\mathrm{CC}$ & Correlation codevector \\
\hline $\mathrm{CCD}$ & Charge-coupled device \\
\hline CCSDS & Consultative Committee for Space Data Systems \\
\hline CDS & Coded dataset \\
\hline $\mathrm{CE}$ & Compression engine \\
\hline CEM & Constraint energy minimization \\
\hline CEOS & Committee on Earth Observation Satellites \\
\hline CFDP & CCSDS File Delivery Protocol \\
\hline CGT & Codebook generation time \\
\hline CHRIS & Compact high-resolution imaging spectrometer \\
\hline $\mathrm{CR}$ & Compression ratio \\
\hline CrIS & Cross-track Infrared Sounder \\
\hline CRISM & Compact Reconnaissance Imaging Spectrometer for Mars \\
\hline CRT & Complex ridgelet transform \\
\hline CSCI & Component software-configurable item \\
\hline $\mathrm{CT}$ & Coding time \\
\hline $\mathrm{CT}$ & Computation time \\
\hline $\mathrm{CV}$ & Codevector \\
\hline CVQ & Correlation vector quantizer \\
\hline $\mathrm{CZT}$ & Cadmium-zinc-telluride \\
\hline DAAC & Distributed active archive center \\
\hline $\mathrm{DC}$ & Digital count \\
\hline $\mathrm{DCT}$ & Discrete cosine transform \\
\hline DCWG & Data Compression Working Group \\
\hline DIV & Difference in variance \\
\hline DLP & Diagonal linear projection \\
\hline DLS & Diagonal linear shrinker \\
\hline DMA & Direct memory access \\
\hline $\mathrm{DN}$ & Digital number \\
\hline DPCM & Differential pulse code modulation \\
\hline DSP & Digital signal processor \\
\hline DT & Decoding time \\
\hline
\end{tabular}




\begin{tabular}{|c|c|}
\hline DTCWT & Dual-tree complex wavelet transform \\
\hline DWT & Discrete wavelet transform \\
\hline EDU & Engineering demonstration unit \\
\hline EM & Endmember \\
\hline EnMAP & Envrionmental Mapping Analysis \\
\hline EOS & Earth Observing System \\
\hline ETF & Electronically tunable filter \\
\hline ETM & Enhanced thematic mapper \\
\hline ETM+ & Enhanced thematic mapper plus \\
\hline EUMETSAT & $\begin{array}{l}\text { European Organization for the Exploitation of Meterologi- } \\
\text { cal Satellites }\end{array}$ \\
\hline EV & Earth view \\
\hline EZW & Embedded zerotrees of wavelet transforms \\
\hline FCLSLU & Fully constrained least-squares linear unmixing \\
\hline FER & Frame-error rate \\
\hline FFT & Fast Fourier transform \\
\hline FIFO & First-in first-out \\
\hline FIPPI & Fast iterative pixel purity index \\
\hline FIR & Far-infrared \\
\hline $\mathrm{FOV}$ & Field of view \\
\hline F-P filter & Fabry-Pérot filter \\
\hline FPA & Focal plane array \\
\hline FPGA & Field programmable gate array \\
\hline FPR & False positive rate \\
\hline FPVQ & Fast precomputed vector quantization \\
\hline FR & Full reference \\
\hline FRIT & Finite ridgelet transform \\
\hline FTHSI & Fourier Transform Hyperspectral Imager \\
\hline FTS & Fourier transform spectrometer \\
\hline FWHM & Full width at half maximum \\
\hline GIFTS & Geosynchronous Imaging Fourier Transform Spectrometer \\
\hline GLA & Generalized Lloyd algorithm \\
\hline GLAS & Geoscience Laser Altimeter System \\
\hline GPO2 & Golomb power-of-two coding \\
\hline GSD & Ground sample distance \\
\hline GUI & Graphical user interface \\
\hline HIBR & Hyperspectral image browser \\
\hline HIS & Intensity-hue-saturation \\
\hline $\mathrm{HPF}$ & High-pass filter \\
\hline HRG & High-Resolution Geometrical \\
\hline HRV & High-Resolution Visible \\
\hline HRVIR & High-Resolution Visible and Infrared \\
\hline $\mathrm{HS}$ & Histogram-based segmentation \\
\hline
\end{tabular}




\begin{tabular}{|c|c|}
\hline HSOCVQ & Hierarchical self-organizing cluster vector quantization \\
\hline HVS & Human visual system \\
\hline HYDICE & Hyperspectral Digital Image Collection Experiment \\
\hline IARR & Internal average relative reflectance \\
\hline IASI & Infrared atmospheric sounding interferometer \\
\hline IBP & Iterative back-projection \\
\hline $\mathrm{IC}$ & Isoclustering \\
\hline $\mathrm{IC}$ & Integrated circuit \\
\hline ICESat & Ice, Cloud, and Land Elevation Satellite \\
\hline IEA & Iterative error analysis \\
\hline IFOV & Instantaneous field of view \\
\hline IFTS & Imaging Fourier transform spectrometer \\
\hline IIR & Imaging Infrared Radiometer \\
\hline IRMSS & Infrared Multispectral Scanner \\
\hline ISO & International Organization for Standardization \\
\hline ISRO & Indian Space Research Organization \\
\hline IWT & Integer wavelet transform \\
\hline JAXA & Japan Aerospace Exploration Agency \\
\hline JPL & Jet Propulsion Laboratory \\
\hline KLT & Karhunen-Loéve transform \\
\hline LAI & Leaf area index \\
\hline LAIS & Locally averaged interband scaling \\
\hline LBG & Linde-Buzo-Gray \\
\hline LCMV-CBS & $\begin{array}{l}\text { Linearly constrained minimum variance constrained band } \\
\text { selection }\end{array}$ \\
\hline LCTF & Liquid crystal tunable filter \\
\hline LDC & Lossless data compression \\
\hline LDCM & Landsat Data Continuity Mission \\
\hline LDPC & Low-density parity check \\
\hline LITE & Lidar In-space Technology Experiment \\
\hline LLE & Locally linear embedding \\
\hline LOCO & Low-complexity lossless compression \\
\hline LOLA & Lunar Orbiter Laser Altimeter \\
\hline LOS & Line of sight \\
\hline LRO & Lunar Reconnaissance Orbiter \\
\hline LSU & Linear spectral unmixing \\
\hline LUT & Lookup table \\
\hline M3 & Moon Mineralogy Mapper \\
\hline MAD & Maximum absolute difference \\
\hline MAE & Mean absolute error \\
\hline MC 3D-EZBC & $\begin{array}{l}\text { Motion-controlled three-dimensional embedded zeroblock } \\
\text { coding }\end{array}$ \\
\hline MCT & Mercury-cadmium-telluride \\
\hline
\end{tabular}




\begin{tabular}{|c|c|}
\hline MDD & Minimum distance detection \\
\hline MDP & Minimum distance partition \\
\hline MDS & Minimal distance selector \\
\hline MEI & Morphological eccentricity index \\
\hline MERIS & Medium-Resolution Imaging Spectrometer \\
\hline MGS & Mars Global Surveyor \\
\hline MHS & Modified histogram-based segmentation \\
\hline MIR & Middle-infrared \\
\hline MISR & Multi-angle imaging spectroradiometer \\
\hline MLA & Mercury Laser Altimeter \\
\hline MNF & Minimum noise fraction \\
\hline M-NVQ & Mean-normalized vector quantization \\
\hline MODIS & Moderate-resolution imaging spectroradiometer \\
\hline MOLA & Mars Orbiter Laser Altimeter \\
\hline MOMS & Modular optoelectronic multispectral scanner \\
\hline MOS & Modular optoelectronic scanner \\
\hline MPS & Mean-distance-order partial search \\
\hline $\mathrm{MRO}$ & Mars Reconnaissance Orbiter \\
\hline MS & Multispectral \\
\hline MSA & Maximum spectral angle \\
\hline MSCA & Multiple-subcodebook algorithm \\
\hline MSE & Mean square error \\
\hline MSID & Maximum spectral information divergence \\
\hline MSS & Multispectral Scanner \\
\hline MSSE & Mean square spectral error \\
\hline MSX & Midcourse Space Experiment \\
\hline MT & Multi-thresholding \\
\hline MTF & Modulation transfer function \\
\hline NDVI & Normalized difference vegetation index \\
\hline $\mathrm{NE} \Delta \mathrm{T}$ & Noise-equivalent change in temperature \\
\hline NGST & Next-Generation Space Telescope \\
\hline NIR & Near-infrared \\
\hline NIST & National Institute of Standards and Technology \\
\hline NN & Nearest neighbor \\
\hline NNP & Nearest-neighbor predictor \\
\hline NPS & Nearest partition set \\
\hline NR & No reference \\
\hline NR & Noisy radiance \\
\hline NRR & Noise-removed radiance \\
\hline NWP & Numerical weather prediction \\
\hline OPD & Optical path difference \\
\hline OSP & Orthogonal subspace projection \\
\hline PALSAR & Phased Array-type L-band Synthetic Aperture Radar \\
\hline
\end{tabular}




\begin{tabular}{|c|c|}
\hline PCA & Principal component analysis \\
\hline PCB & Print circuit board \\
\hline PD & Probability of detection \\
\hline PDS & Partial distance search \\
\hline PDS & Planetary Data System \\
\hline PFA & Probability of false alarm \\
\hline PMAD & Percentage maximum absolute difference \\
\hline PPI & Pixel purity index \\
\hline PRISM & $\begin{array}{l}\text { Panchromatic Remote-sensing Instrument for Stereo } \\
\text { Mapping }\end{array}$ \\
\hline PROBA & Project for Onboard Autonomy \\
\hline PSF & Point spread function \\
\hline PSNR & Peak signal-to-noise ratio \\
\hline PT & Processing time \\
\hline QLUT & Quantized-index lookup table \\
\hline RBV & Return Beam Vidicon \\
\hline RDCT & Reversible discrete cosine transform \\
\hline RE & Ratio enhancement \\
\hline REP & Red-edge position \\
\hline ReRMSE & Relative root mean square error \\
\hline RF & Radio frequency \\
\hline RGB & Red-green-blue \\
\hline RMSE & Root mean square error \\
\hline RMSSE & Root mean square spectral error \\
\hline $\mathrm{ROC}$ & Receiver operating characteristic \\
\hline ROI & Region of interest \\
\hline RR & Reduced reference \\
\hline RTDLT & Reversible time-domain lapped transform \\
\hline SA & Spectral angle \\
\hline SAM & Spectral angle mapper \\
\hline SAMVQ & Successive approximation multistage vector quantization \\
\hline SAR & Synthetic aperture radar \\
\hline $\mathrm{SC}$ & Spectral correlation \\
\hline ScaRaB & Scanner for radiation budget \\
\hline SCPS & Space Communications Protocol Specifications \\
\hline SDD & Standard deviation difference \\
\hline SeaWiFS & Sea-viewing wide-field-of-view sensor \\
\hline SEU & Single-event upset \\
\hline SFBBC & Spectral-feature-based binary code \\
\hline SFF & Spectral feature fitting \\
\hline SFFS & Sequential forward-floating selection \\
\hline S-FMP & Spectral fuzzy-matching pursuits \\
\hline SFS & Sequential forward selection \\
\hline
\end{tabular}




\begin{tabular}{|c|c|}
\hline SFSI & Short-Wave Infrared Full-Spectrum Imager \\
\hline SGA & Simplex growing algorithm \\
\hline SID & Sub-identity \\
\hline SLA & Shuttle Laser Altimeter \\
\hline SLSQ & Spectrum-oriented least squares \\
\hline SNR & Signal-to-noise ratio \\
\hline SOAD/SOSD & Sum of absolute/squared distance \\
\hline SOFM & Self-organizing feature map \\
\hline SPIHT & Set partitioning in hierarchical trees \\
\hline SPIM & Spectrographic imager \\
\hline SPOT & Système Pour l'Observation de la Terre \\
\hline SRBC & Solar-radiation-based calibration \\
\hline SRF & Spectral response function \\
\hline S-RLP & Spectral relaxation-labeled prediction \\
\hline SSE & Sum of squared error \\
\hline SSIM & Structural similarity \\
\hline SSR & Solid state recorder \\
\hline SV & Spectral vector \\
\hline SVM & Support vector machine \\
\hline SVR & Synthetic variable ratio \\
\hline SWIR & Short-wavelength infrared \\
\hline $\mathrm{TC}$ & Telecommand \\
\hline TDLT & Time-domain lapped transform \\
\hline TDM & Time-division multiplex \\
\hline TERM & Triangular elementary reversible matrix \\
\hline TES & Tropospheric Emission Spectrometer \\
\hline TIE & Triangle inequality elimination \\
\hline TM & Thematic Mapper \\
\hline $\mathrm{TMC}$ & Thematic Mapper calibrator \\
\hline TOA & Top of atmosphere \\
\hline TPR & True positive rate \\
\hline USES & Universal source encoder for space \\
\hline UVISI & Ultraviolet and Visible Imagers and Spectrographic Imagers \\
\hline VA & Vector accumulator \\
\hline VCA & Vertex component analysis \\
\hline VD & Virtual dimensionality \\
\hline VHDL & $\begin{array}{l}\text { Very high-speed integrated-circuit hardware description } \\
\text { language }\end{array}$ \\
\hline VI & Vegetation index \\
\hline VIF & Visual information fidelity \\
\hline VLSI & Very large scale integration \\
\hline VM & Verification model \\
\hline VNIR & Visible and near-infrared \\
\hline
\end{tabular}




$\begin{array}{ll}\text { VQ } & \text { Vector quantization } \\ \text { WER } & \text { Word-error rate } \\ \text { WFC } & \text { Wide-Field Camera } \\ \text { WGCV } & \text { Working Group on Calibration and Validation } \\ \text { WPT } & \text { Wavelet-package transform } \\ \text { WT } & \text { Wavelet transform } \\ \text { XML } & \text { Extensible markup language } \\ \text { ZC } & \text { Zero crossing }\end{array}$

